\title{
Persistent altered mental status
}

Manuel A. Cabrera, MD, Kelsey S. Hobart, MD, and Jacqueline Posada, MD

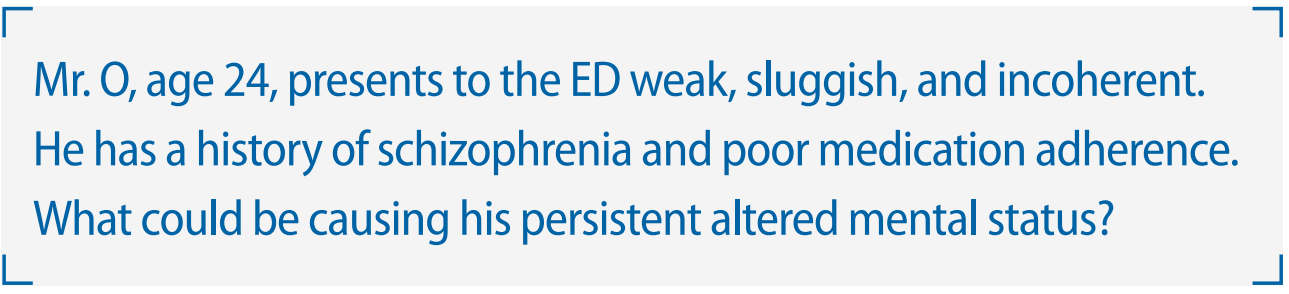

\section{CASE Sluggish, weak, and incoherent}

Mr. 0 , age 24, who has a history of schizophrenia and obesity, presents to the emergency department (ED) for altered mental status (AMS). His mother reports that he has been sluggish, weak, incoherent, had no appetite, and that on the day before admission, he was drinking excessive amounts of water and urinating every 10 minutes.

\section{HISTORY Multiple ineffective antipsychotics}

Mr. O was diagnosed with schizophrenia at age 21 and struggled with medication adherence, which resulted in multiple hospitalizations for stabilization. Trials of haloperidol, risperidone, paliperidone palmitate, and valproic acid had been ineffective. At the time of admission, his psychotropic medication regimen is fluphenazine decanoate, $25 \mathrm{mg}$ injection every 2 weeks; clozapine, $50 \mathrm{mg} / \mathrm{d}$; lithium carbonate, $300 \mathrm{mg}$ twice a day; benztropine, 2 mg every night; and trazodone, 50 mg every night.

\section{EVALUATION Fever, tachycardia, and diabetic ketoacidosis}

Upon arrival to the ED, Mr. $\mathrm{O}$ is obtunded, unable to follow commands, and does not respond to painful stimuli. On physical exam, he has a fever of $38.4^{\circ} \mathrm{C}$ (reference range $35.1^{\circ} \mathrm{C}$ to $37.9^{\circ} \mathrm{C}$ ); tachycardia with a heart rate of 142 beats per minute (bpm) (reference range 60 to 100); tachypnea with a respiratory rate of 35 breaths per minute (reference range 12 to 20); a blood pressure of $116 / 76 \mathrm{mmHg}$ (reference range $90 / 60$ to $130 / 80$ ); and hypoxemia with an oxygen saturation of $90 \%$ on room air (reference range $94 \%$ to $100 \%$ ).

Mr. $\mathrm{O}$ is admitted to the hospital and his laboratory workup indicates diabetic ketoacidosis (DKA), with a glucose of $1,700 \mathrm{mg} / \mathrm{dL}$; anion gap of 30 (reference range 4 to $12 \mathrm{mmol} / \mathrm{L}$ ); $\mathrm{pH} 7.04$ (reference range 7.32 to 7.42 ); serum bicarbonate 6 (reference range 20 to $24 \mathrm{mEq} / \mathrm{L}$ ); beta-hydroxybutyrate 11.04 (reference range 0 to $0.27 \mathrm{mmol} / \mathrm{L}$ ); urine ketones, serum osmolality 407 (reference range 280 to $300 \mathrm{mOsm} / \mathrm{kg}$ ); and an elevated white blood cell count of 18.4 (reference range 4.5 to $\left.11.0 \times 10^{9} / \mathrm{L}\right)$. A CT scan of the head is negative for acute pathology.

Dr. Cabrera is a PGY-3 Internal Medicine Resident, Department of DC. Dr. Hobart is a PGY-3 Psychiatry Resident, Department of Psychiatry and Department of Behavioral Health, St. Elizabeths Hospital, Washington, DC. Dr. Posada is Clinical Assistant Professor, Department of Psychiatry and Behavioral Sciences, The George Washington University, Washington, DC.

\section{Disclosures}

The authors report no financial relationships with any companies whose products are mentioned in this article, or with manufacturers of competing products.

doi: $10.12788 /$ cp. 0180 continued on page 47 Internal Medicine, The George Washington University, Washington,

\section{How would you handle this case?}

Answer the challenge questions at MDedge.com/ psychiatry and see how your colleagues responded 
Initially, all psychotropic medications are held. On Day 3 of hospitalization, psychiatry is consulted and clozapine, $50 \mathrm{mg} / \mathrm{d}$; lithium, $300 \mathrm{mg} / \mathrm{d}$; and benztropine, $1 \mathrm{mg}$ at night, are restarted; however, fluphenazine decanoate and trazodone are held. The team recommends IV haloperidol, $2 \mathrm{mg}$ as needed for agitation; however, it is never administered.

Imaging rules out deep vein thrombosis, cardiac dysfunction, and stroke, but a CT chest scan is notable for bilateral lung infiltrates, which suggests aspiration pneumonia.

Mr. $\mathrm{O}$ is diagnosed with diabetes, complicated by DKA, and is treated in the intensive care unit (ICU). Despite resolution of the DKA, he remains altered with fever and tachycardia.

On Day 6 of hospitalization, Mr. $O$ continues to be tachycardic and obtunded with nuchal rigidity. The team decides to transfer Mr. $\mathrm{O}$ to another hospital for a higher level of care and continued workup of his persistent AMS.

Immediately upon arrival at the second hospital, infectious disease and neurology teams are consulted for further evaluation. Mr. O's AMS continues despite no clear signs of infection or other neurologic insults.

\section{At this point, what is the most pressing concern?}
a) lung infiltrates
b) nuchal rigidity
c) obtunded mental state
d) persisting tachycardia

\section{The authors' observations}

Based on Mr. O's psychiatric history and laboratory results, the first medical team concluded his initial AMS was likely secondary to DKA; however, the AMS continued after the DKA resolved. At the second hospital, Mr. O's treatment team continued to dig for answers.

\section{EVALUATION Exploring the differential diagnosis}

At the second hospital, Mr. $\mathrm{O}$ is admitted to the ICU with fever $\left(37.8^{\circ} \mathrm{C}\right)$, tachycardia
(120 bpm), tachypnea, withdrawal from painful stimuli, decreased reflexes, and muscle rigidity, including clenched jaw. The differential diagnoses include meningitis, sepsis from aspiration pneumonia, severe metabolic encephalopathy with prolonged recovery, central pontine myelinolysis, anoxic brain injury, and subclinical seizures.

Empiric vancomycin, $1.75 \mathrm{~g}$ every 12 hours; ceftriaxone, $2 \mathrm{~g} / \mathrm{d}$; and acyclovir, $900 \mathrm{mg}$ every 8 hours are started for meningoencephalitis, and all psychotropic medications are discontinued. Case reports have documented a relationship between hyperglycemic hyperosmolar syndrome (HHS) and malignant hyperthermia in rare cases ${ }^{1}$; however, HHS is ruled out based on Mr. O's laboratory results. A lumbar puncture and imaging rules out CNS infection. Antibiotic treatment is narrowed to ampicillin-sulbactam due to Mr. O's prior CT chest showing concern for aspiration pneumonia. An MRI of the brain rules out central pontine myelinolysis, acute stroke, and anoxic brain injury, and an EEG shows nonspecific encephalopathy. On Day 10 of hospitalization, a neurologic exam shows flaccid paralysis and bilateral clonus, and Mr. O is mute. On Day 14 of hospitalization, his fever resolves, and his blood cultures are negative. On Day 15 of hospitalization, Mr. O's creatine kinase (CK) level is elevated at 1,308 $\mathrm{U} / \mathrm{L}$ (reference range 26 to $192 \mathrm{U} / \mathrm{L}$ ), suggesting rhabdomyolysis.

Given the neurologic exam findings, and the limited evidence of infection, the differential diagnosis for Mr. O's AMS is broadened to include catatonia, neuroleptic malignant syndrome (NMS), serotonin syndrome, and autoimmune encephalitis. The psychiatry team evaluates $\mathrm{Mr}$. $\mathrm{O}$ for catatonia. He scores 14 on the Bush-Francis Catatonia Rating Scale, with findings of immobility/stupor, mutism, staring, autonomic instability, and withdrawal indicating the presence of catatonia. ${ }^{2}$

\section{The authors' observations}

When $\mathrm{Mr}$. O was transferred to the second hospital, the primary concern was to rule

\section{Clinical Point}

Based on Mr. O's psychiatric history and laboratory results, the first medical team concluded his initial AMS was likely secondary to DKA

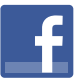

Discuss this article at www.facebook.com/ MDedgePsychiatry $\mathbf{Q}$ 


\section{Clinical Point}

Given the neurologic
exam findings, and
limited evidence
of infection, the
differential diagnosis
for Mr. O's AMS is
broadened

\section{broadened}

\section{Table 1}

\section{Diagnostic criteria for neuroleptic malignant syndrome}

\begin{tabular}{|c|c|}
\hline Feature & Description \\
\hline Exposure to a dopamine antagonist & First- or second-generation antipsychotic use \\
\hline Hyperthermia & $>100.4^{\circ} \mathrm{F}$ or $>38.0^{\circ} \mathrm{C}$ on at least 2 occasions \\
\hline Rigidity & Rigidity is usually of the "lead-pipe rigidity" type \\
\hline Altered mental status & Hyperactive or hypoactive delirium \\
\hline Serum creatine kinase elevation & At least 4 times the upper limit of normal \\
\hline Sympathetic nervous system lability & $\begin{array}{l}\text { Blood pressure elevation, } \geq 25 \% \text { above baseline } \\
\text { Blood pressure fluctuation, } \geq 20 \mathrm{mmHg} \text { (diastolic) or } \\
\geq 25 \mathrm{mmHg} \text { (systolic) changes within } 24 \text { hours } \\
\text { Tachycardia, } \geq 25 \% \text { above baseline } \\
\text { Tachypnea, } \geq 50 \% \text { above baseline }\end{array}$ \\
\hline Negative workup for other etiologies & - \\
\hline \multicolumn{2}{|c|}{ "Atypical” or early neuroleptic malignant syndrome } \\
\hline \multicolumn{2}{|l|}{ Rigidity may be milder or absent } \\
\hline \multicolumn{2}{|l|}{ Fever might be absent } \\
\hline \multicolumn{2}{|c|}{$\begin{array}{l}\text { Any } 2 \text { of the symptoms list above in the setting of an offending agent, and other medical causes of the } \\
\text { symptoms have been ruled out }\end{array}$} \\
\hline
\end{tabular}

out meningitis due to his unstable vitals, obtunded mental state, and nuchal rigidity. A comprehensive infectious workup, including lumbar puncture, was imperative because infection can not only lead to AMS, but also precipitate episodes of DKA. Mr. O's persistently abnormal vital signs indicated an underlying process may have been missed by focusing on treating DKA.

\section{TREATMENT Finally, the diagnosis is established}

A lorazepam challenge is performed, and Mr. 0 receives $4 \mathrm{mg}$ of lorazepam over 24 hours with little change in his catatonia symptoms. Given his persistent fever, tachycardia, and an elevated CK levels in the context of recent exposure to antipsychotic medications, $\mathrm{Mr}$. $\mathrm{O}$ is diagnosed with NMS (Table $\mathbf{1}^{3,4}$ ) and is started on bromocriptine, $5 \mathrm{mg} 3$ times daily.

\section{What is the mechanism of action of bromocriptine?}

a) N-methyl-D-aspartate (NMDA) receptor antagonist
b) positive allosteric modulator of GABA-A receptor
c) postsynaptic dopamine D2 receptor agonist
d) skeletal muscle relaxant

\section{The authors' observations}

Mr. O's complicated medical state-starting with DKA, halting the use of antipsychotic medications, and the suspicion of catatonia due to his history of schizophrenia-all distracted from the ultimate diagnosis of NMS as the cause of his enduring AMS and autonomic instability. Catatonia and NMS have overlapping symptomatology, including rigidity, autonomic instability, and stupor, which make the diagnosis of either condition complicated. A positive lorazepam test to diagnose catatonia is defined as a marked reduction in catatonia symptoms (typically a 50\% reduction) as measured on a standardized rating scale..$^{5}$ However, a negative lorazepam challenge does not definitely rule out catatonia because some cases are resistant to benzodiazepines. ${ }^{6}$ 


\section{Pharmacologic treatment of neuroleptic malignant syndrome}

\begin{tabular}{|c|c|c|}
\hline Medication and dosage & Mechanism of action & Notes \\
\hline $\begin{array}{l}\text { Lorazepam, } 1 \text { to } 2 \mathrm{mg} \text { IM } \\
\text { or IV every } 4 \text { to } 6 \text { hours } \\
\text { Diazepam, } 10 \text { mg IV every } \\
8 \text { hours }\end{array}$ & $\begin{array}{l}\text { Positive allosteric modulator } \\
\text { of GABA-A receptor }\end{array}$ & $\begin{array}{l}\text { Mild to moderate cases } \\
\text { Administer with or without } \\
\text { bromocriptine or amantadine }\end{array}$ \\
\hline $\begin{array}{l}\text { Bromocriptine, } 2.5 \text { to } 5 \mathrm{mg} \\
\text { by mouth every } 8 \text { hours }\end{array}$ & $\begin{array}{l}\text { Postsynaptic dopamine D2 } \\
\text { receptor agonist }\end{array}$ & $\begin{array}{l}\text { Moderate to severe cases } \\
\text { Counteract } D 2 \text { blockade of } \\
\text { antipsychotics } \\
\text { Administration should be by mouth } \\
\text { and can be via feeding tube }\end{array}$ \\
\hline $\begin{array}{l}\text { Amantadine, } 100 \mathrm{mg} \text { by } \\
\text { mouth every } 8 \text { hours }\end{array}$ & $\begin{array}{l}\text { Nonspecific: Direct increase } \\
\text { of dopamine release, } \\
\text { reduce dopamine reuptake, } \\
\text { anticholinergic, weak NMDA } \\
\text { receptor antagonist }\end{array}$ & Moderate to severe cases \\
\hline $\begin{array}{l}\text { Dantrolene, } 1 \text { to } 2.5 \mathrm{mg} / \mathrm{kg} \mathrm{IV} \\
\text { every } 6 \text { hours }\end{array}$ & $\begin{array}{l}\text { Blocks calcium efflux from } \\
\text { sarcoplasmic reticulum to } \\
\text { directly relax skeletal muscle }\end{array}$ & Most severe cases \\
\hline
\end{tabular}

NMS risk factors relevant in this case include male sex, young age, acute medical illness, dehydration, and exposure to multiple psychotropic medications, including 2 antipsychotics, clozapine and fluphenazine. ${ }^{7}$ DKA is especially pertinent due to its acute onset and cause of significant dehydration. NMS can occur at any point of antipsychotic exposure, although the risk is highest during the initial weeks of treatment and during dosage changes. Unfortunately, Mr. O's treatment team was unable to determine whether his medication had been recently changed, so it is not known what role this may have played in the development of NMS. Although first-generation antipsychotics are considered more likely to cause NMS, second-generation antipsychotics (SGAs) dominate the treatment of schizophrenia and bipolar disorder, and these medications also can cause NMS. ${ }^{8}$ As occurred in this case, long-acting injectable antipsychotics can be easily forgotten when not administered in the hospital, and their presence in the body persists for weeks. For example, the half-life of fluphenazine decanoate is approximately
10 days, and the half-life of haloperidol decanoate is 21 days. ${ }^{9}$

\section{OUTCOME Improvement with bromocriptine}

After 4 days of bromocriptine, $5 \mathrm{mg} 3$ times daily, Mr. $\mathrm{O}$ is more alert, able to say "hello," and can follow 1-step commands. By Day 26 of hospitalization, his CK levels decrease to $296 \mathrm{U} / \mathrm{L}$, his CSF autoimmune panel is negative, and he is able to participate in physical therapy. After failing multiple swallow tests, $\mathrm{Mr}$. $\mathrm{O}$ requires a percutaneous endoscopic gastrostomy (PEG) tube. He is discharged from the hospital to a long-term acute care facility with the plan to taper bromocriptine and restart a psychotropic regimen with his outpatient psychiatrist. At the time of discharge, he is able to sit at the edge of the bed independently, state his name, and respond to questions with multiple-word answers.

\section{Which medication can most safely be used in} the future to treat Mr. O's schizophrenia?

a) aripiprazole extended-release injectable suspension

\section{Clinical Point}

Catatonia and NMS have overlapping symptomatology, which make the diagnosis of either condition complicated 


\section{Clinical Point}

The most common pharmacologic treatments for NMS are dantrolene, bromocriptine, benzodiazepines, and amantadine
b) clozapine
c) chlorpromazine
d) quetiapine

\section{The authors' observations}

The most common pharmacologic treatments for NMS are dantrolene, bromocriptine, benzodiazepines (lorazepam or diazepam), and amantadine. ${ }^{3}$ Mild cases of NMS should be treated with discontinuation of all antipsychotics, supportive care, and benzodiazepines. ${ }^{3}$ Bromocriptine or amantadine are more appropriate for moderate cases and dantrolene for severe cases of NMS. ${ }^{3}$ All antipsychotics should be discontinued while a patient is experiencing an episode of NMS; however, once the NMS has resolved, clinicians must thoroughly evaluate the risks and benefits of restarting antipsychotic medication. After a patient has experienced an episode of NMS, clinicians generally should avoid prescribing the agent(s) that caused NMS and long-acting injections, and slowly titrate a low-potency SGA such as quetiapine. ${ }^{10}$ Table $2^{3,11,12}$ (page 49 ) outlines the pharmacologic treatment of NMS.

\section{References}

1. Zeitler P, Haqq A, Rosenbloom A, et al. Hyperglycemic hyperosmolar syndrome in children: pathophysiological considerations and suggested guidelines for treatment. J Pediatr. 2011;158(1):9-14.e1-2. doi: 10.1016/j. jpeds.2010.09.048

2. Francis A. Catatonia: diagnosis, classification, and treatment. Curr Psychiatry Rep. 2010;12(3):180-185. doi: 10.1007/ s11920-010-0113-y

3. Pileggi DJ, Cook AM. Neuroleptic malignant syndrome. Ann Pharmacother. 2016;50(11):973-981. doi:10.1177/ 1060028016657553

\section{Related Resource}

- Turner AH, Kim JJ, McCarron RM. Differentiating serotonin syndrome and neuroleptic malignant syndrome. Current Psychiatry. 2019;18(2):30-36.

Drug Brand Names

Acyclovir · Zovirax

Amantadine $\cdot$ Gocovri

Ampicillin-sulbactam .

Unasyn

Aripiprazole • Abilify

Maintena

Benztropine $\cdot$ Cogentin

Bromocriptine - Cycloset

Parlodel

Ceftriaxone $\cdot$ Rocephin

Clozapine $\cdot$ Clozaril

Dantrolene $\cdot$ Dantrium

4. Gurrera RJ, Caroff SN, Cohen A, et al. An international consensus study of neuroleptic malignant syndrome diagnostic criteria using the Delphi method. J Clin Psychiatry. 2011;72(9):1222-1228. doi:10.4088/JCP.10m06438

5. Sienaert P, Dhossche DM, Vancampfort D, et al. A clinical review of the treatment of catatonia. Front Psychiatry. 2014;5:181. doi:10.3389/fpsyt.2014.00181

6. Daniels J. Catatonia: clinical aspects and neurobiological correlates. J Neuropsychiatry Clin Neurosci. 2009;21(4):371380. doi:10.1176/jnp.2009.21.4.371

7. Bhanushali MJ, Tuite PJ. The evaluation and management of patients with neuroleptic malignant syndrome. Neurol Clin. 2004;22(2):389-411. doi:10.1016/j.ncl.2003.12.006

8. Tse L, Barr AM, Scarapicchia V, et al. Neuroleptic malignant syndrome: a review from a clinically oriented perspective. Curr Neuropharmacol. 2015;13(3):395-406. doi:10.2174/1570 159x13999150424113345

9. Correll CU, Kim E, Sliwa JK, et al. Pharmacokinetic characteristics of long-acting injectable antipsychotics for schizophrenia: an overview. CNS Drugs. 2021;35(1):39-59. doi:10.1007/s40263-020-00779-5

10. Strawn JR, Keck PE Jr, Caroff SN. Neuroleptic malignant syndrome. Am JPsychiatry. 2007;164(6):870-876. doi:10.1176/ ajp.2007.164.6.870

11. Griffin CE 3rd, Kaye AM, Bueno FR, et al. Benzodiazepine pharmacology and central nervous system-mediated effects. Ochsner J. 2013;13(2):214-223.

12. Reulbach U, Dütsch C, Biermann T, et al. Managing an effective treatment for neuroleptic malignant syndrome. Crit Care. 2007;11(1):R4. doi:10.1186/cc5148

\section{Bottom Line}

Neuroleptic malignant syndrome (NMS) should always be part of the differential diagnosis in patients with mental illness and altered mental status. The risk of NMS is especially high in patients with acute medical illness and exposure to antipsychotic medications. 